\title{
Extreme Atlantic hurricane seasons made more likely by ocean warming
}

\author{
Peter Pfleiderer ${ }^{\mathrm{a}, \mathrm{b},},{ }^{*}$, Shruti Nath ${ }^{\mathrm{a}, \mathrm{c}}$, and Carl-Friedrich Schleussner ${ }^{\mathrm{a}, \mathrm{b}}$ \\ ${ }^{a}$ Climate Analytics, Berlin, Germany \\ ${ }^{\mathrm{b}}$ Humboldt University, Geographie, IRI-Thesys, Berlin, Germany \\ ${ }^{\mathrm{c}}$ Eidgenössische Technische Hochschule Zürich, Zürich, Switzerland \\ Correspondence: Peter Pfleiderer (peter.pfleiderer@climateanalytics.org)
}

\begin{abstract}
Tropical cyclones are among the most damaging and fatal extreme weather events. An increase in Atlantic tropical cyclone activity has been observed, but attribution to global warming remains challenging due to large inter-annual variability and modelling challenges. Here we show that the increase in Atlantic tropical cyclone activity since the 1980s can be robustly ascribed to changes in atmospheric circulation as well as sea surface temperature (SST) increase. Using a novel weather

5 pattern based statistical model, we find that the forced warming trend in Atlantic SSTs over the 1982-2018 period increased the probability of extremely active tropical cyclone seasons by $14 \%$. Seasonal atmospheric circulation remains the dominant factor explaining both inter-annual variability and the observed increase. Our weather pattern-based statistical decomposition helps to understand the role of atmospheric variability for the Atlantic tropical cyclone activity and provides a new perspective on the role of ocean warming.
\end{abstract}

\section{Introduction}

Tropical cyclones (TCs) are highly destructive extreme weather events (MunichRe, 2021), with a notable increase in intensity and associated damages over recent decades (Kossin et al., 2013, 2020; Holland and Bruyère, 2014; Knutson et al., 2019). Under anthropogenically caused climate change the impact severity of TCs is exacerbated due to more extreme precipitation (van Oldenborgh et al., 2017; Reed et al., 2020) and increased risk of storm surges following from sea level rise (Lin et al., 2016), amongst others.

Whether the observed increase in TC intensity arises from a long-term trend related to global warming however remains unresolved. While climate models project an increase in TC intensities (Bhatia et al., 2018; Walsh et al., 2016; Knutson et al., 2020), a recent study suggests that after correcting for missing storm observations prior to satellite observation there is no robust long-term trend in Atlantic major hurricane counts (Vecchi et al., 2021).

TC formation and intensification mostly depends on the atmospheric environment which varies strongly on inter-annual and intra-seasonal time-scales. TC formation mainly requires low vertical wind shear and strong low-level relative vorticity (Frank and Ritchie, 2001; Sharmila and Walsh, 2017) alongside some initial perturbation (Dieng et al., 2017). The maximal potential intensity of a storm mostly depends on the vertical temperature gradient from the ocean surface to the upper troposphere (Emanuel, 1987; Emanuel et al., 2013). Whether a storm reaches its maximum potential intensity is however strongly con- 

global warming on changes in TCs globally still exist (Knutson et al., 2019, 2020).

Given the large uncertainty in forced atmospheric circulation changes, and assuming that these changes are small in comparison to internal variability (Trenberth et al., 2015) a promising way forward could be to focus on thermodynamically forced changes instead. Using a numerical TC forecast model, Reed et al. (2020) attributed a portion of the rainfall of hurricane Florence to thermodynamic effects of global warming. This study followed the story-line approach in which dynamical conditions of the weather event are reproduced for different counterfactual thermodynamic forcings. Such approaches are however restricted to individual events with clearly defined atmospheric conditions and cannot be directly generalized to seasonal TC activity (Reed et al., 2020).

For a more generalizable approach, the role of internal variability needs to be established and separated from the potential thermodynamic forcing (Shepherd, 2016). Climate models could be used to this extent (Sippel et al., 2019), but would require a large ensemble of climate simulations with adequate TC representation. Alternatively circulation analogues can be used. For example, Cattiaux et al. (2010) reproduced European winter temperatures based on observed circulation patterns and their influence on local temperatures.

Here we follow the idea of circulation analogues to construct a probabilistic tropical cyclone season emulator based on the empirically assessed influence of atmospheric circulation patterns over the tropical north Atlantic on TC activity. We find that the sequence of weather patterns throughout the main hurricane season (August-October) explains most of the inter-annual variability in number of storms and their intensities. The full observed variability in TC activity can be reproduced by including sea-surface temperatures (SSTs) over the main development region (MDR see fig. S7) as an amplifying factor for most intense TCs. Using counterfactual experiments, we furthermore investigate the extent to which trends in Atlantic SSTs contribute to highly active tropical cyclone seasons under current climatic conditions.

\section{Data and Methods}

\subsection{Data \& Preprocessing}

For the classification of weather patterns we use mean sea level pressure and vertical wind shear calculated as the difference between $200 \mathrm{hPa}$ and $850 \mathrm{hPa}$ eastward wind from the ERA5 reanalysis (Hersbach et al., 2020) over the period 1979-2018. Weather patterns are classified over the tropical north Atlantic (10W-90W and $10 \mathrm{~N}-30 \mathrm{~N})$. In order to remove the direct influence of TCs in the reanalysis data we replace an area of $9^{\circ} \times 9^{\circ}$ around the center of the storm with an average of the grid-cells around this rectangle. Additionally, we regridded the data from a $1^{\circ} \times 1^{\circ}$ grid to a $2.5^{\circ} \times 2.5^{\circ}$ grid and averaged to daily data. For the construction and validation of the TC emulator, we use daily sea surface temperatures from the Daily Optimum Interpolation Sea Surface Temperature (DOISST) data set (Huang et al., 2021). SSTs are averaged over the Atlantic main development region (MDR) defined as 90W-20W and 10N-30N (see figure S7). To assess long-term trends in Atlantic MDR SSTs, the Hadley Centre Sea Ice and Sea Surface Temperature data set (HadISST) is used (Rayner, 2003).

We use TC observations from the official WMO agency provided by the IBTrACKS database (Knapp et al., 2010, 2018). Only 
storms in the Atlantic basin are considered (see figure S3). As a measure for seasonal TC activity we use accumulated cyclone energy:

$60 A C E=10^{-4} \sum v_{\max }^{2}$

Where $v_{\max }$ is the 6 hourly sustained wind speed in knots.

TCs are classified according to the Saffir-Simpson hurricane wind scale according to which TCs with sustained winds of more than 64 knots are named hurricanes and TCs with sustained winds above 96 knots are major hurricanes. Following the definitions of the NOAA national weather service (CPC, 2021) we classify Atlantic hurricane seasons into above normal seasons if they produce more than 126.1 ACE or extremely active seasons if the produced more than 159.6 ACE.

\subsection{Daily tropical Atlantic weather patterns and sea surface temperatures}

We use a self organizing map algorithm (SOM) to classify daily tropical Atlantic weather into 20 patterns. A SOM is an artificial neural network that is used for dimensionality reduction and can be applied to classify synoptic weather patterns (Hewitson and Crane, 2002). Here we reduce the highly dimensional information of mean sea level pressure (MSLP) and vertical wind shear (VWS) over a $2.5^{\circ} \times 2.5^{\circ}$ grid spanning $10 \mathrm{~N}-30 \mathrm{~N}$ and $90 \mathrm{~W}-10 \mathrm{~W}$ to a $5 \times 4$ map where each node represents a weather pattern (see figure S1-2).

Instead of randomly initializing the SOM we use 20 clusters obtained from a k-means clustering as initial conditions. This k-means clustering is performed on a Sammon projection of the original data. The advantage of this initialization is that we have one clearly defined initialization and do not have to select one SOM result from a number of random initializations.

To guarantee that both variables (MSLP and VWS) have equal weight in the classification we standardize the variables to the 1980-2010 mean and standard deviation. The combination of these two variables is a suitable choice for our application as TC formation and intensification strongly depends on VWS while MSLP is generally helpful to characterize the prevailing atmospheric circulation.

Some selected weather patterns are shown in figure 1: Strongest TC activity is observed during weather pattern w15 which is characterized by a large low-pressure anomaly and nearly no vertical wind shear in the east of the MDR. Strong VWS in this region leads to fewer and weaker storms (see weather pattern w12). A strong high-pressure anomaly as in weather pattern w1 is similarly TC inhibiting. A weak pressure gradient from east to west with low VWS in the MDR is associated with moderate TC activity (w6). All 20 weather patterns are shown in the supplementary material (figures S1, S2, S4).

The intensities of TCs also depend on SSTs in the region. As shown in figure S10, strongest storms are found over warm 85 SSTs. A quantile regression shows a significant relationship between warm SSTs and above median TC intensities. Weather patterns are not fully independent from SSTs: weather patterns with low pressure anomalies occur more often on days with warm SST anomalies (see figure 1 blue bars). However, no systematic association between SSTs and VWS is apparent (see figure S1 and S4). Although we will not be able to treat our weather patterns as independent from SST anomalies in the region, both variables contain distinct information that is relevant for TC intensification. 


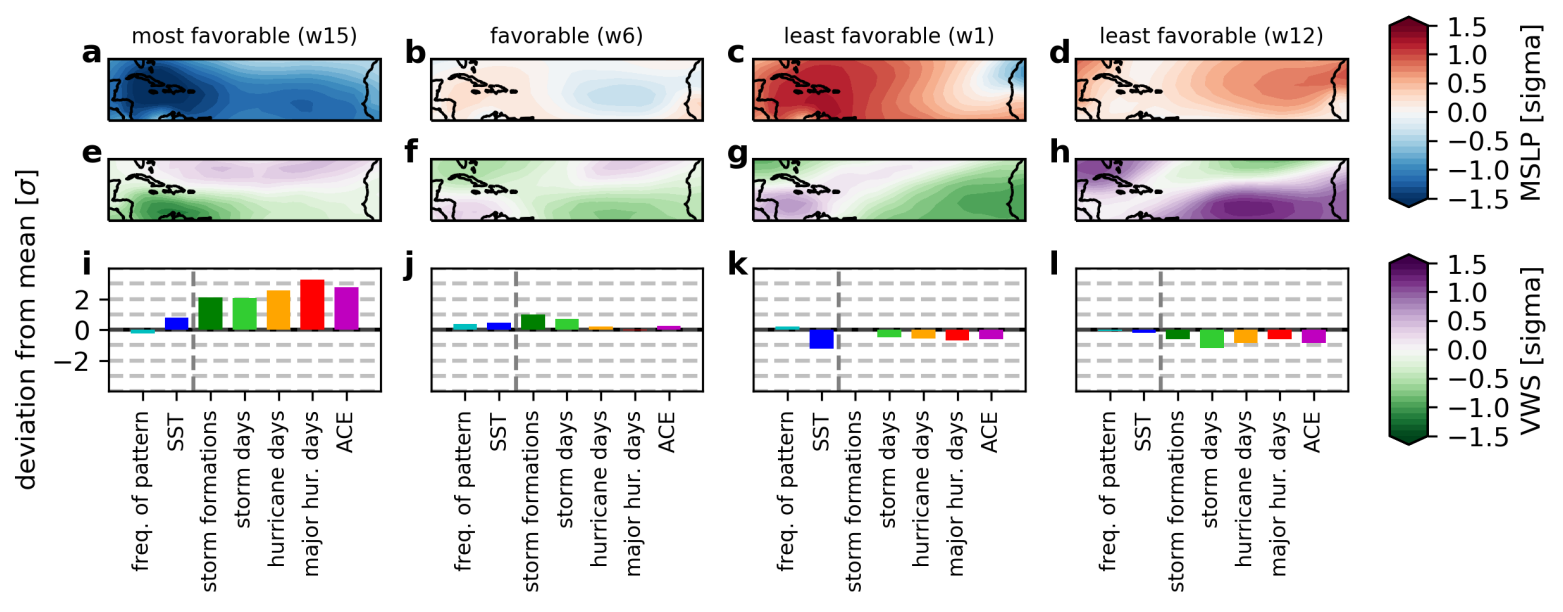

Figure 1. Tropical cyclone activity during selected weather patterns. Mean sea level pressure anomalies (a-d) and vertical wind shear anomalies (e-h) for four selected weather patterns w15, w6, w1 and w12. The last row (i-l) shows relative deviations from the average of all weather patterns expressed in standard deviations for the following statistics: frequency of the weather pattern, SST in the MDR, number of storm formations during the weather pattern, storm days, hurricane days, major hurricane days and average ACE generated during days with this weather pattern. A value of 2 indicates, that the statistic is 2 standard deviations higher during this weather pattern than for the average over all weather patterns. All 20 weather patterns are shown in figures S1, S2, S4

\subsection{Seasonal Tropical Cyclone Emulator}

We construct a probabilistic emulator that creates series of storms with maximum sustained wind speeds for each day. TCs are rare events and their formation and intensification involves complex physical processes. In our emulator we break these processes down into three components that are fully independent from each other: i) storm formation, ii) storm duration, iii) daily storm intensity. In these components the daily weather pattern slightly alters the probabilities for a new storm formation and it's duration and the weather pattern in combination with regionally averaged SSTs alters the probabilities for intensification of an existing storm (see figure 2).

\subsubsection{Storm formation}

The number of storm formations varies strongly between different large scale weather patterns (Jaye et al., 2019). Storm formation predominantly occurs during weather patterns with low vertical wind shear, high relative humidity in the lower troposphere and the existence of some kind of perturbation. The component relies on the following assumptions: i) Weather patterns can favour or hamper storm formations, ii) persistent weather conditions can further increase or decrease formation probabilities. 


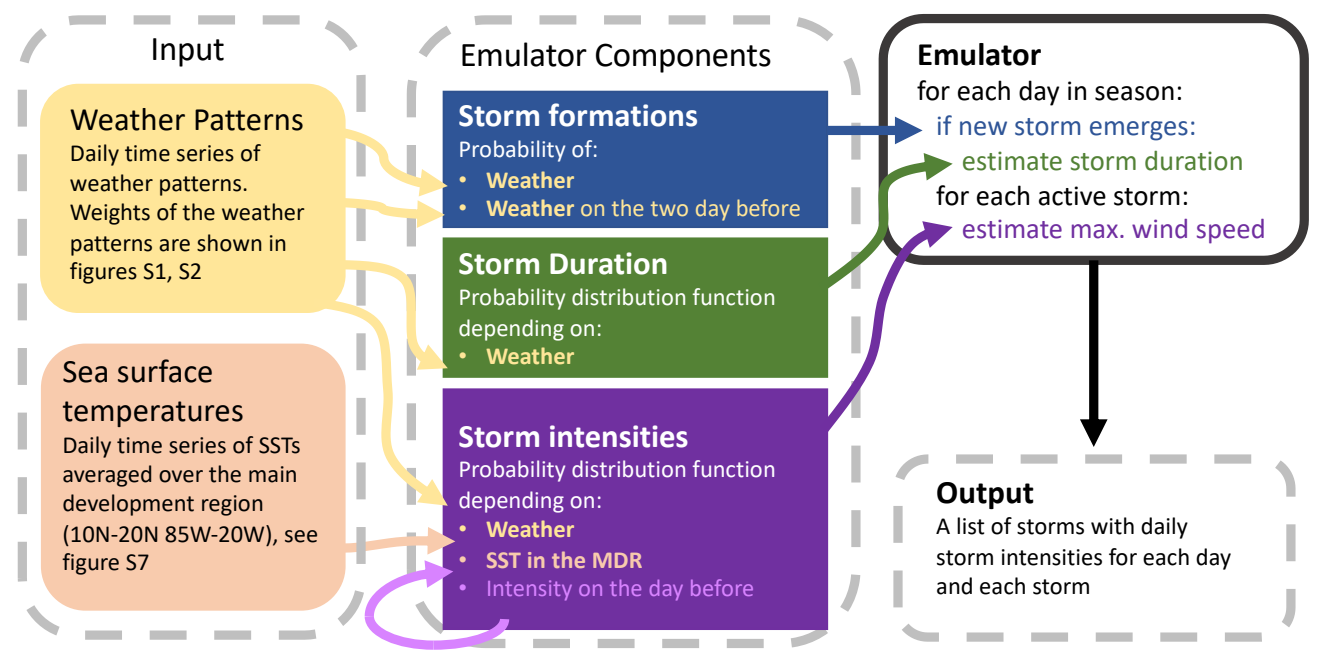

Figure 2. Schematic overview of the emulator. The input required to emulate TC seasons is shown on the left side. In the center, the three components of the emulator are listed. On the right side, the functioning of the emulator is sketched and the format of the output is indicated. Arrows between the left hand columns indicate which input is used in which components of the emulator.

Based on these assumptions we estimate the probability of a storm formation event $P_{g e n}$ on a day $d$ with weather pattern $w(d)$ as:

$P_{g e n}(d)=P_{o b s}(g e n \mid w(d)) * \frac{\sqrt{P_{o b s}\left(g e n_{+1 d} \mid w(d-1)\right) * P_{o b s}\left(g e n_{+2 d} \mid w(d-2)\right)}}{P_{o b s}(g e n \mid a l l)}$

The first factor $P_{o b s}(g e n \mid w(d))$ is the observed probability of storm formations for the given weather pattern $w$. The second factor includes the probabilities of storm formations one and two days after the weather pattern that occurred one $\left(P_{o b s}\left(g_{e n} n_{+1 d} \mid w(d-1)\right)\right)$ and two $\left(P_{o b s}\left(g_{e n} n_{+2 d} \mid w(d-2)\right)\right)$ days earlier respectively. These probabilities are given less weight by applying a square root and the factor is normalized by a dividing by the overall observed storm formation probability $110\left(P_{\text {obs }}(\right.$ gen $\mid$ all $\left.)\right)$.

\subsubsection{Storm duration}

There are numerous processes that can weaken and eventually dissipate TCs. The most common end of a TC is landfall. As we do not have information about the location of storms in our emulator, estimating the duration of a storm is challenging. For the development of this component we use the following assumptions: i) storms dissipate when making landfall, ii) the time a storm has before making landfall is modulated by its formation location, iii) the formation location is to some extend influenced by weather patterns (see figure S5). 
$D(s)=f_{g}\left(D_{\text {obs }}\left[w_{\text {row }}-w_{\text {row }}\left(d_{f}\right)<2 \& w_{\text {col }}-w_{\text {col }}\left(d_{f}\right)<2\right]\right)$

\subsubsection{Storm intensity}

We quantify storm intensity through the daily maximum sustained wind speed. We use the following assumptions for our daily storm intensity emulations: i) intensification can be favored or hampered by weather patterns, ii) the intensity of a storm depends on the intensity on the day before, iii) warmer SSTs in the MDR favour the intensification of strong TCs, iv) the relationship between SSTs and storm strength can be regularized by a quantile regression.

Assessing probability density functions for daily storm intensities for all possible combinations of weather patterns, SSTs, and storm intensities on the day before is challenging given the insufficient number of storm observations. Therefore, instead of estimating a PDF for the daily intensity from all observations that match to certain conditions (e.g. weather pattern w6, $28^{\circ} \mathrm{C}$ SST and 60kts wind speed on the day before) we estimate the intensity PDF from the 100 storm observations that are most similar to these conditions.

Furthermore, the distribution of observed intensities is skewed towards weak storms which would result in a low intensity bias in a straight forward application of the nearest neighbors approach (see figure S13). We therefore introduce a linear relationship between regionally averaged SSTs and storm intensities (see quantile regression in figure S10) to guarantee that the intensities from which we sample are not systematically to weak.

For a given $S S T_{\text {target }}$ we transform all observed storm intensities to artificial pseudo-intensities $v_{\text {shifted }}$ using the slope $\beta_{\tau}$ of the next quantile $\tau$ below the observed storm strength $v(s, d)$ :

$v_{\text {shifted }}\left(s, d, S S T_{\text {target }}\right)=v(s, d)+\beta_{\tau(s, d)} *\left(S S T_{\text {target }}-S S T_{\text {obs }}(d)\right)$

$\tau(s, d)=\min \left(\tau: v(s, d)>\beta_{\tau}+c_{\tau}\right)$

We use the Euclidean distance metric applied on standardized variables to identify the 100 nearest neighbors in terms of weather pattern and storm intensity on the day before:

$D\left(d_{i}, d_{j}\right)^{2}=\frac{\left(w\left(d_{i}\right)-w\left(d_{j}\right)\right)^{2}}{\sqrt{\frac{1}{N} \sum_{m}\left(w\left(d_{m}\right)-\bar{w}\right)^{2}}}+\frac{\left(v_{\text {shifted }}\left(d_{i}-1\right)-v_{\text {shifted }}\left(d_{j}-1\right)\right)^{2}}{\sqrt{\frac{1}{N} \sum_{m}\left(v_{\text {shifted }}\left(d_{m}\right)-\overline{v_{\text {shifted }}}\right)}}$

For the weather patterns, which are not a continuous variable, we consider their coordinates in the SOM grid as locations and calculate differences between weather patterns as the sum of the squared differences in row and column numbers.

$w\left(d_{i}\right)-w\left(d_{j}\right)=\sqrt{\left(w_{\text {row }}\left(d_{i}\right)-w_{\text {row }}\left(d_{j}\right)\right)^{2}+\left(w_{\text {col }}\left(d_{i}\right)-w_{\text {col }}\left(d_{j}\right)\right)^{2}}$ 


\section{Results}

\subsection{Validation of the emulator}

Figure 3 sketches the functioning of the emulator for three Atlantic hurricane seasons: 2017 was a highly active season with predominantly warm SSTs and favorable large-scale weather conditions allowing for strong TCs throughout most of the season. 2016 had similarly warm SSTs but less favorable weather conditions resulting in overall fewer days with strong storms. 1983 was an El Niño year with cool SSTs in the tropical Atlantic and mostly unfavorable weather conditions for TCs in the Atlantic basin. The chance of finding storms and especially the chance of finding major hurricanes in simulations (fig. 3d) for the respective years reflects the observed weather patterns and SSTs.

To validate the emulator, we re-simulated every hurricane season between 1982 and 20181000 times using the observed sequence of daily weather patterns and SST averages over the MDR. We construct a new emulator for each decade using all the years but the decade we want to re-simulate as training data.

Large scale weather patterns are sufficient to explain most of the inter-annual variations in the number of storm formations (see fig. 4A). The remaining spread between individual simulation runs is to be expected as tropical storm formations have a strong stochastic component. Besides favorable weather conditions, storm formation requires a (small scale) perturbation in the atmospheric flow such as African easterly waves to be initiated (Dieng et al., 2017), information that is lacking in our emulator.

The number of storm days per season is strongly related to the number of storms. The simulated storm durations enhance the representation of number of storm days resulting in a accurate representation of storm durations (see fig. S6, S25) and a Pearson rank correlation coefficient of 0.68 between observations and the median of all simulations (see fig. 4B).

Finally, the storm intensity component produces a variety of storm intensities including major hurricanes (see fig. 4C). As for the number of storm days the number of strong storms is tightly linked to the number of storm formations. But as storm intensification is favored by certain weather patterns and warm SSTs, the potential for intensification alters between years. In combination, this results in an adequate representation of inter-annual variability in seasonal accumulated cyclone energy (ACE) as shown in figure $4 \mathrm{D}$.

\subsection{Sensitivity analysis}

Strong simplifications were required to emulate TCs based on sequences of weather patterns and regionally averaged SSTs. The assumptions on which our methodological choices are made are plausible and appear to work well, they are however not without alternatives. We therefore test how alternative emulators perform.

The most critical part is the treatment of SSTs in the intensification component of the emulator as it directly influences some of the results. As shown in table S3 (also figures S22, S23, S24), emulators without any SST influence have significant trends in residuals for ACE (15 ACE per decade) and the number of major hurricanes (4 maj. hurricanes per decade). Including SSTs into the intensification component of the emulator reduces these trends significantly which suggests, that SSTs contain information that is required for an adequate representation of strongest TCs. 


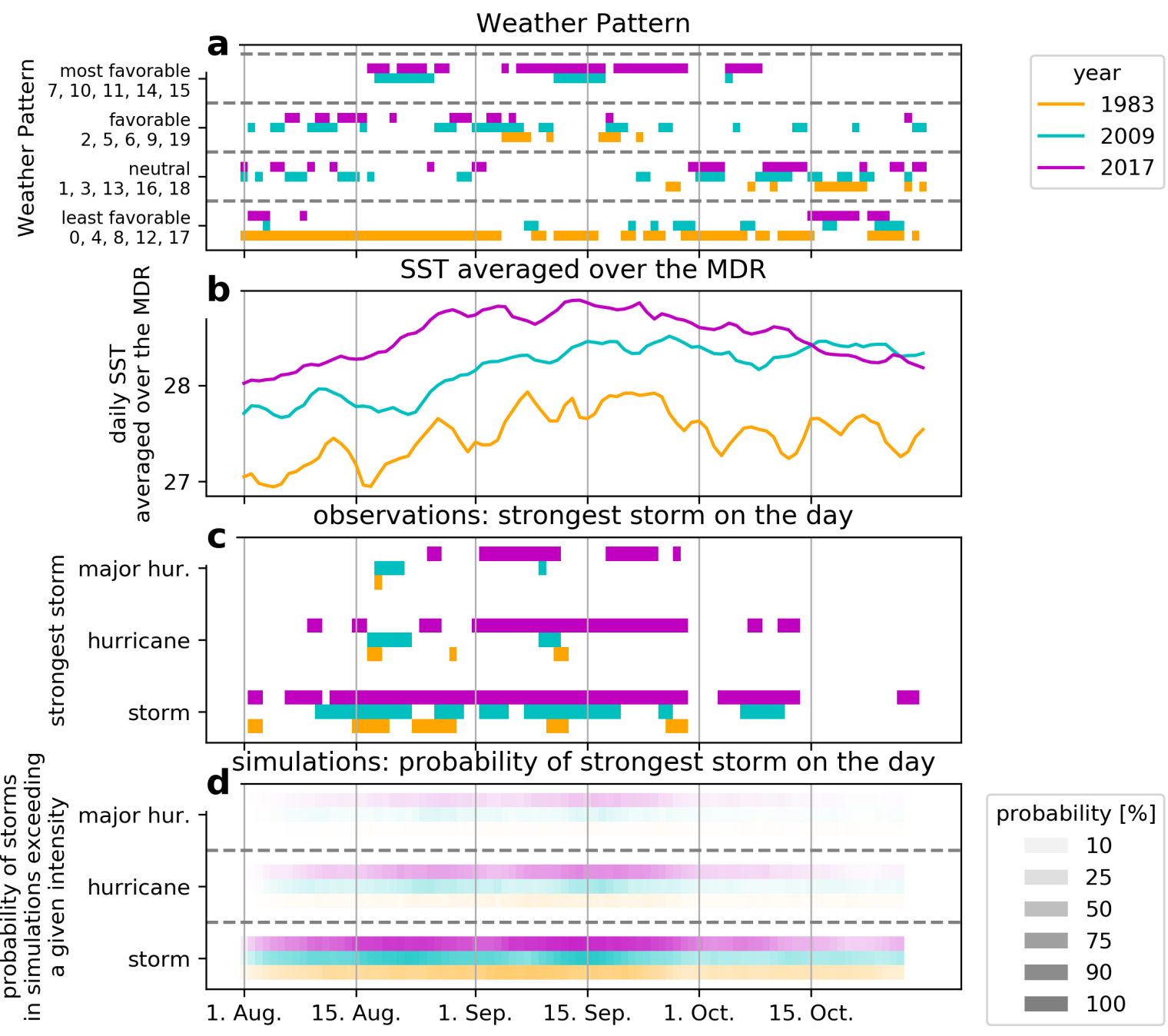

Figure 3. Functioning of the tropical cyclone emulator. a, Sequence of daily weather patterns grouped into four categories from least favorable for TC formation and intensification to most favorable for the years 2017 (purple), 2016 (cyan) and 1983 (orange). b, Daily SSTs averaged over the main development region for the same years. c, Intensity of the strongest storm for each day grouped into the categories storm, hurricane and major hurricane. d, Probability of exceeding the intensity thresholds of $\mathrm{c}$ in simulations from the emulator.

A simpler way of including SSTs in our emulator could be to estimate intensity probability functions directly from the 100 nearest neighbors in terms of weather patterns, storm intensities on the day before and SSTs. While this approach works well in the range of average conditions, there are systematic deviations between the nearest neighbors and the target conditions for more extreme conditions. As shown in figure S12 there is a warm bias for cool SSTs and vice versa which is a result of to few observations from which the nearest neighbors can be searched. Similarly, there is a bias towards weaker storms in the nearest neighbors (see figure S13 S14). Reducing the number of nearest neighbors from 100 to 20 only slightly reduces these biases. 

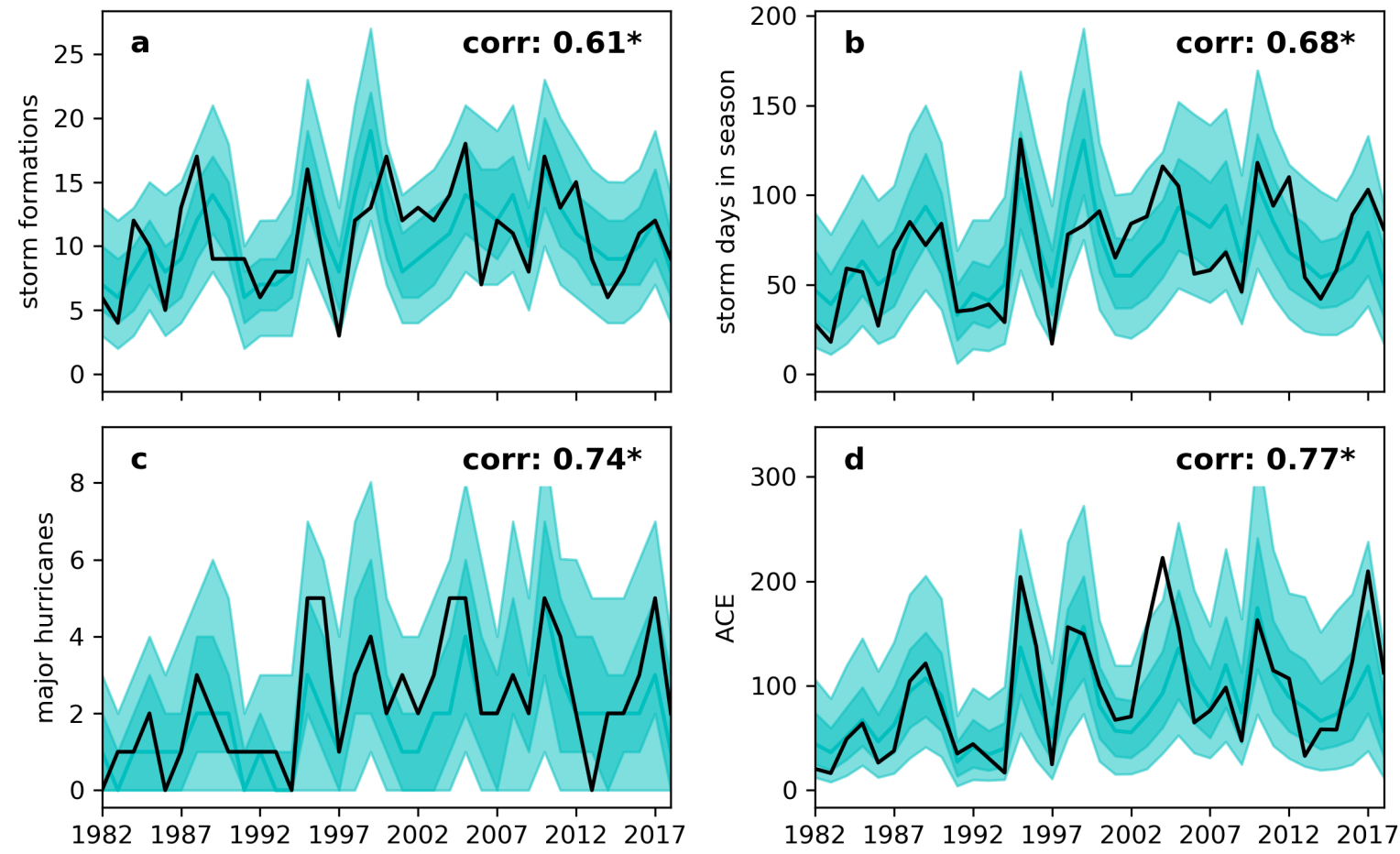

Figure 4. Cross validated hurricane season emulations. a, Number of storms as observed (black) and simulated (cyan). The light shading shows the $95 \%$ range of the 1000 simulations, the darker shading shows the $66 \%$ range. The median is indicated by a solid line. The cross validated Pearson correlation coefficient between hindcasts and observations is indicated in the legend (see methods for more details on the decadal cross validation). b, As a but for the number of storm days in a season. $\mathbf{c}$, As a but for the number of major hurricanes in a season. d, As a but for the seasonal ACE.

Ultimately, this results in a lack of sensitivity in our emulator that leads to a systematic underestimation of strongest TCs (see figures S23 S24).

In the supplementary information we present a number of additional emulators with slightly altered storm formation, storm duration and storm intensity components. Most of these altered emulators yield similar results which supports the robustness of our results.

\subsection{Understanding recent TC variability}

We deploy the emulator to assess the contributions of large scale atmospheric circulation and long-term warming of tropical Atlantic SSTs towards the likelihood of extremely active hurricane seasons. Over the period 1982-2018, SSTs in the Atlantic MDR have warmed at a rate of $0.3 K$ per decade (fig. S8). This is a considerably stronger trend than the long-term trend of 
https://doi.org/10.5194/wcd-2021-64

Preprint. Discussion started: 7 October 2021

(C) Author(s) 2021. CC BY 4.0 License.
Weather and

Climate Dynamics

Discussions

$0.05 K$ per decade for the period 1850-2018 (S9). Thus most of the SST trend over the 1982-2018 period is a result of internal variability.

To disentangle forced changes from internal variability we construct counterfactual scenarios in which we remove the longterm SST trend from the 1982-2018 observations and then shift these SST time-series so that on average they match the values of the long-term trend at three years: 2018, 1982 and 1900 (e.g. pre-industrial). We thereby obtain three counterfactual scenarios of stable climate for different SST levels, all sharing identical internal variabilities (see fig. 5a). For all scenarios we re-simulate each year of the period 1982-2018 1000 times using the observed weather pattern sequences, a counterfactual SST time series and the emulator trained on the years 1982-2008.

Over the period 1982-2018, large scale atmospheric circulation patterns are the dominant factor explaining year to year variability in TC activity. Our emulations show high TC activity in the same years irrespective of the counterfactual SSTs (see fig. 5b). For instance, the low activity in the years 1982-1987 is also simulated in the experiment with 2018's SST levels while the years 1995, 2005, 2010 and 2017 have a high likelihood of becoming an extremely active season also with 1982's SST levels.

Nevertheless, differences in seasonal TC activity are apparent between the different scenarios. On average, the seasonal activity is 5 ACE lower for 1982's SST levels as compared to 2018's SST levels (see fig. 5c). Consequently, the probability of a season becoming an above normal season is $11 \%$ lower in the 1982 scenario (an above normal seasonal activity being defined as > 126.1 ACE (CPC, 2021)).

Differences between the counterfactual scenarios are stronger in years with high TC activity (see fig. 5c). For years in which half of the simulations with 2018's SST levels are above normal seasons, the simulations are on average 10 ACE more active with 2018's SST levels than with 1982's SST levels. For these years the risk of finding an extremely active season (with ACE $>159.6$ ) drops from $44 \%$ under current climate to $38 \%$ under 1982's SSTs (see fig. 5g).

Assuming that the observed relationship between TC activity and regionally averaged SSTs can be extrapolated outside of the period 1982-2018, we simulate Atlantic hurricane seasons as we would expect them with pre-industrial SSTs (only few years with particularly low TC activity lie outside of the data on which the emulator was trained, see gray shading in figure 5a).

According to our simulations the hurricane activity of the recent decades would have been significantly lower under preindustrial SSTs. Compared to the 2018's SST levels, the average seasonal activity is 15 ACE lower in the pre-industrial experiment resulting in 9\% lower likelihood of finding an above normal season. While in our emulator the influence of $0.5 \mathrm{~K}$ SST warming has a remarkable effect on highly active hurricane seasons, weather patterns remain the dominant factor influencing the potential of becoming an active season.

Simulations from the emulator can moreover be used to analyze contributions to extremely damaging hurricane seasons such as that of 2017. 2017 is in the top 10 most active recorded hurricane seasons with 225 ACE and 6 major hurricanes, characterized by weather patterns that are favorable for TC formation and intensification and relatively warm SSTs. Figure 6a shows the probabilities of finding such a season under counterfactual SST scenarios. 

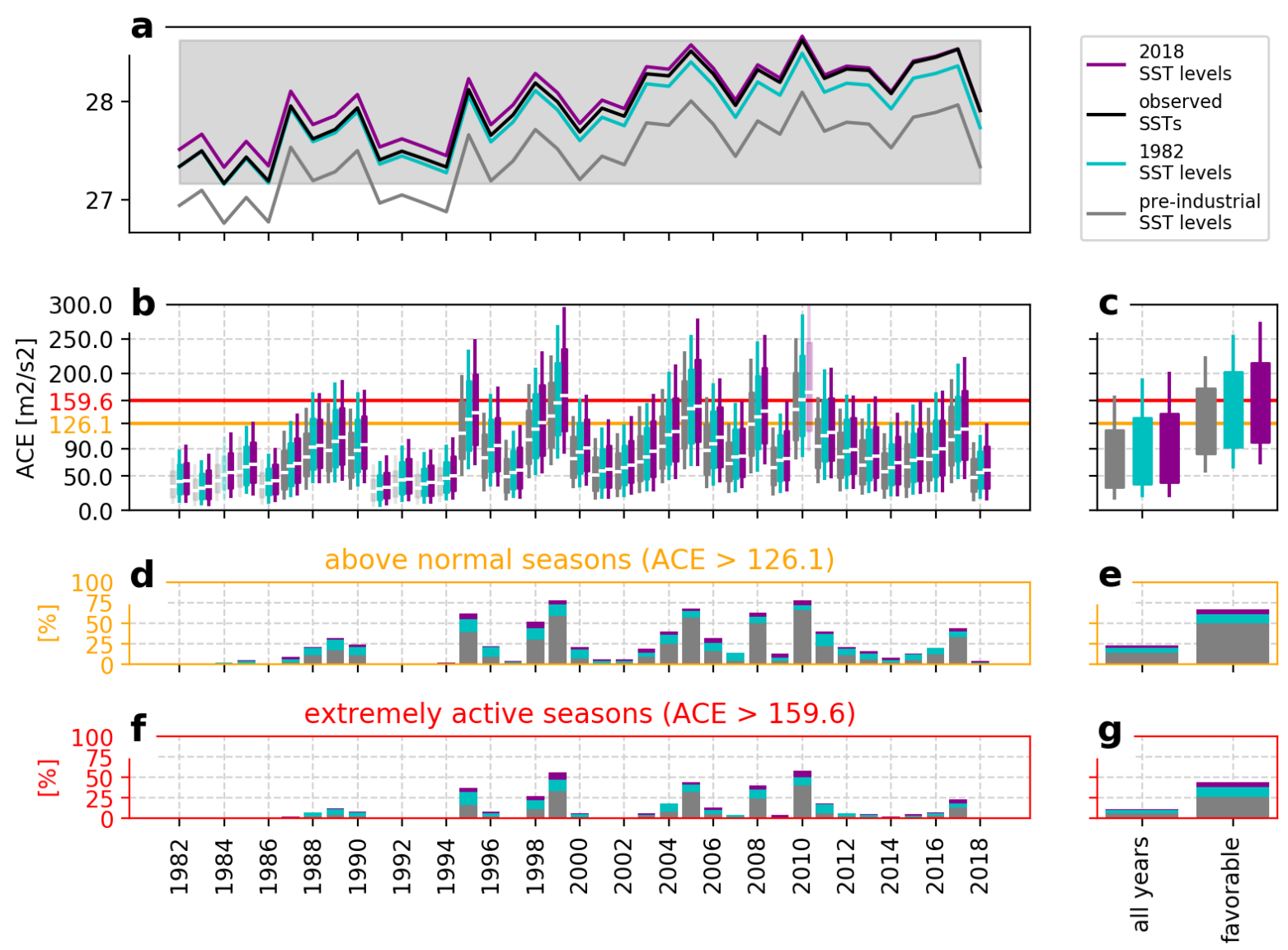

Figure 5. Atlantic hurricane seasons under different counterfactual SST scenarios. a, Observed SSTs averaged over the Atlantic MDR (black) and three counterfactual scenarios: SSTs from which the long-term SST trend has been removed and that are shifted to 2018 SST levels (purple), shifted to 1982 SST levels (cyan) and shifted to 1900 SST levels (gray). b, Simulations for the counterfactual scenarios of a. c, Simulations for all years aggregated and for the most favorable years defined as years for which half of the simulations in the current SST scenario have more than 126.1 ACE. d, Probability of above normal seasons (ACE > 126.1). e, As d but for all years and favorable years. $\mathbf{f}$, as $\mathbf{d}$ but for extremely active seasons (ACE > 159.6). $\mathbf{g}$, As e but for extremely active seasons. 

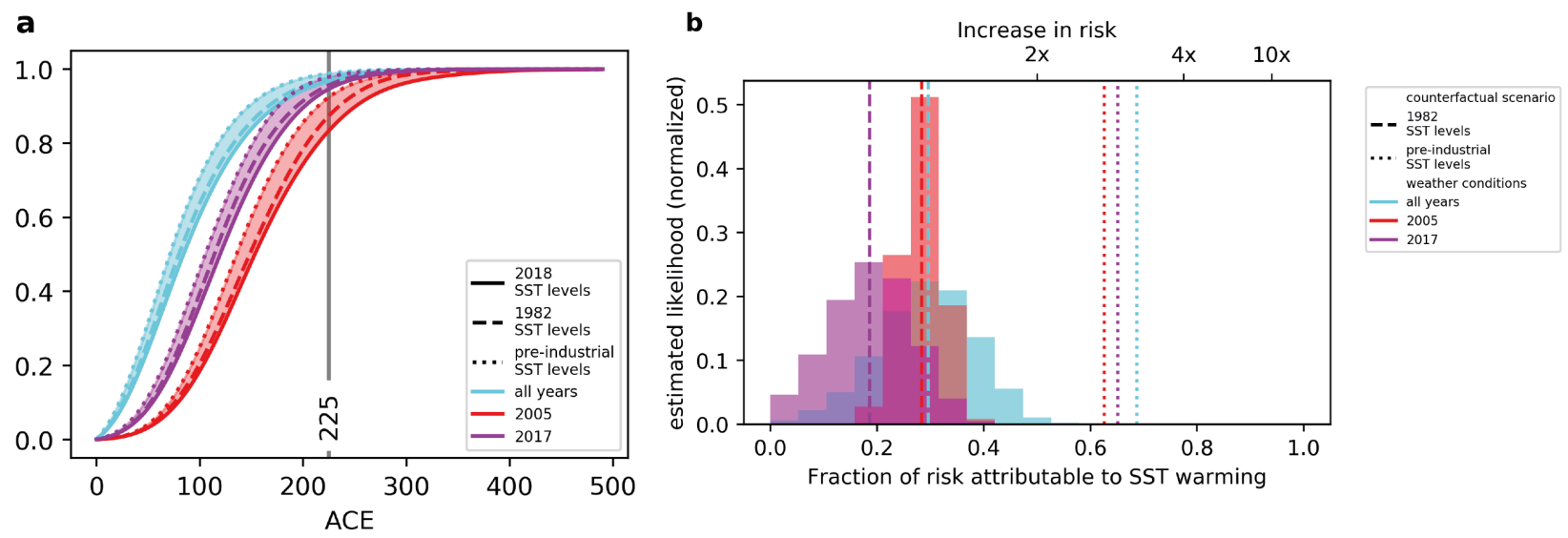

Figure 6. Influence of ocean warming on the hurricane season 2017. a, Cumulative distribution functions for seasonally aggregated ACE for the three scenarios: current SST levels (solid), 1982's SST levels (dashed) and pre-industrial SST levels (dotted). All years between 1982-2018 aggregated in cyan, 2017 in purple and 2005 in red. The area between the 2018 scenario and the pre-industrial scenario is shaded. The horizontal gray line indicates 225 ACE which was observed in 2017. b. Fraction of risk of an ACE $>225$ season attributable to the SST difference between the 2018's SST levels and 1982's SST levels (dashed lines) and 2018's SST levels and pre-industrial SST levels (dotted lines). The histograms show the FAR distributions from a 10000-member bootstrapping for the 1982 SST level scenario, the horizontal lines indicate the median FARs.

Compared to other years, 2017 has a high probability of becoming an above normal season (44\%) and a considerable probability of becoming an extremely active season $(23 \%)$. Nevertheless, the observed activity was rather exceptional with only $4 \%$ of the simulations reaching the observed ACE of 225 (see fig. 6a).

Under a counterfactual scenario of early 1980's with similar modes of internal climate variability, weather patterns and short term variations in Atlantic SSTs, the season would have less likelihood to become an above normal hurricane season (40\%) or even an extremely active season (19\%).

For 2017 weather conditions, the warming of Atlantic SSTs since the 1980s makes finding a season with 225 ACE $20 \%$ more likely (see fig. 6b). For a year like 2005 which according to our analysis had a higher likelihood of becoming an extremely active season than 2017, the fraction of risk that can be attributed to the long-term SST warming since the 1980 is even higher than for 2017 (30\%).

An extrapolation of our model to pre-industrial SSTs suggests, that the likelihood of extremely active seasons such as 2017 would have been significantly lower with pre-industrial SSTs. In such, the chance of finding an extremely active season under 2017 's conditions would have been $13 \%$ instead of $23 \%$ with pre-industrial versus current SST levels. 


\section{Discussion and conclusions}

We have demonstrated that the observed Atlantic tropical cyclone activity over the last 40 years can be reproduced with a probabilistic emulator based on large-scale weather patterns and SSTs. Over this period, we observe a trend in weather patterns favoring more active TC seasons. Whether or not this trend can be attributed climate change or other external drivers such as aerosol loading's (Dunstone et al., 2013) remains an open question.

Our weather patterns and regional SST time series are not fully independent. Specifically, it appears that years with warm Atlantic SSTs are also years where Atlantic SSTs are warm relative to the rest of the tropics and it has been argued, that this effect of relative SSTs is the dominant contribution to TC activity (Sobel et al., 2016; Murakami et al., 2018). The temperature difference between the tropical Atlantic and other tropical basins has a strong impact on atmospheric circulation. However, our sensitivity analysis suggests, that SSTs over the MDR contain relevant information and that our approach to include SSTs in the emulator as an addition to the sequences of weather patterns is suited to simulate intense TCs. The potential maximum intensity a TC can reach depends on the temperature difference between the ocean surface and the tropopause layer and it is plausible, that increasing SSTs have an amplifying effect on strong TCs (Emanuel, 1987). However, it has been argued that over the satellite era, tropopause layer cooling might have dominated over the role of SSTs (Emanuel et al., 2013), a hypothesis we cannot exclude based on our analysis.

Ultimately, the integration of SSTs in our model relies on assumptions that are pysically motivated and that lead to a better representation of TC activity over the period 1982-2018 than other assumptions. Since the early 1980's, global warming of more than $0.5 \mathrm{~K}$ has occured and we would argue that over this period SSTs in the region serve as a useful proxy for thermodynamic changes in the climate system. However, given some of the model limitations highlighted above, we refrain from making a climate change attribution statement of the observed changes in cyclone activity and caveat extrapolated assessments of changes relativ to pre-industrial conditions.

There is increasing consensus in the scientific literature that the number of tropical cyclones might not or only moderately increase, while the number of most intense storms would increase substantially (Masson-Delmotte et al., In Press). Our emulator results indicate that increasing SSTs could be a potential driver for such an intensification.

By separating out the thermodynamic and dynamic changes for observed ACE, our approach allows us to link the observed trend in seasonal cyclone activity and extreme season probability to warming SSTs. Our findings indicate that warming SSTs over the tropical Atlantic might have already contributed significantly to more extreme tropical cyclone seasons, and thereby to the fatalities, destruction and trillion dollar losses that these cyclones have caused over this the last four decades (MunichRe, 2021). Given the projected increases of SSTs with increasing warming, our findings suggest that the probability of extreme seasons might further increase. To minimise future risks, achieving net-zero $\mathrm{CO} 2$ emissions and stringent emission reductions in other greenhouse gases would be required to halt global warming in line with the goal of the Paris Agreement (MassonDelmotte et al., In Press). 
https://doi.org/10.5194/wcd-2021-64

Preprint. Discussion started: 7 October 2021

(c) Author(s) 2021. CC BY 4.0 License.

(c) (i)

Weather and

Climate Dynamics

Discussions

Code availability. All python scripts required to perform the analysis and create the plots is available under https://doi.org/10.5281/zenodo.

2705176003.

Author contributions. P.P. and C.-F.S. conceived the study. P.P. developed the methods with contributions from C.-F.S. and S.N.. P.P. prepared all figures. P.P. wrote the manuscript with contributions from all authors.

Competing interests. No competing interests.

Acknowledgements. We acknowledge the NOAA's International Best Track Archive for Climate Stewardship (IBTrACS), the fifth generation 275 of ECMWF atmospheric reanalyses (ERA5), the Optimum Interpolation Sea Surface Temperature (or daily OISST) from NOAA and the Hadley Centre Sea Ice and Sea Surface Temperature data set (HadISST). P.P. and C.-F.S. acknowledge support by the German Federal Ministry of Education and Research (01LN1711A). S.N. was supported by the LAMACLIMA project, receiving funding from the German Federal Ministry of Education and Research (BMBF) and the German Aerospace Center (DLR) as part of AXIS, an ERANET initiated by JPI Climate (grant no. 01LS1905A), with co-funding from the European Union (grant no. 776608). 
https://doi.org/10.5194/wcd-2021-64

Preprint. Discussion started: 7 October 2021

(C) Author(s) 2021. CC BY 4.0 License.
Weather and

Climate Dynamics

Discussions
280

Bhatia, K., Vecchi, G., Murakami, H., Underwood, S., and Kossin, J.: Projected Response of Tropical Cyclone Intensity and Intensification in a Global Climate Model, Journal of Climate, pp. JCLI-D-17-0898.1, https://doi.org/10.1175/JCLI-D-17-0898.1, 2018.

Cattiaux, J., Vautard, R., Cassou, C., Yiou, P., Masson-Delmotte, V., and Codron, F.: Winter 2010 in Europe: A Cold Extreme in a Warming Climate: COLD WINTER 2010 IN EUROPE, Geophysical Research Letters, 37, n/a-n/a, https://doi.org/10.1029/2010GL044613, 2010.

Climate Prediction Center - Atlantie Hurricane Outlook, https.//www.cpe.ncep.noaa.gov/products/outlooks/Background.html, 2021.

Dieng, A. L., Sall, S. M., Eymard, L., Leduc-Leballeur, M., and Lazar, A.: Trains of African Easterly Waves and Their Relationship to Tropical Cyclone Genesis in the Eastern Atlantic, Monthly Weather Review, 145, 599-616, https://doi.org/10.1175/MWR-D-15-0277.1, 2017.

Dunstone, N. J., Smith, D. M., Booth, B. B. B., Hermanson, L., and Eade, R.: Anthropogenic Aerosol Forcing of Atlantic Tropical Storms,

Emanuel, K., Solomon, S., Folini, D., Davis, S., and Cagnazzo, C.: Influence of Tropical Tropopause Layer Cooling on Atlantic Hurricane Activity, Journal of Climate, 26, 2288-2301, https://doi.org/10.1175/JCLI-D-12-00242.1, 2013.

Emanuel, K. A.: The Dependence of Hurricane Intensity on Climate, Nature, 326, 3, 1987.

Frank, W. M. and Ritchie, E. A.: Effects of Vertical Wind Shear on the Intensity and Structure of Numerically Simulated Hurricanes, Monthly Weather Review, 129, 2249-2269, https://doi.org/10.1175/1520-0493(2001)129<2249:EOVWSO>2.0.CO;2, 2001.

Hersbach, H., Bell, B., Berrisford, P., Hirahara, S., Horányi, A., Muñoz-Sabater, J., Nicolas, J., Peubey, C., Radu, R., Schepers, D., Simmons, A., Soci, C., Abdalla, S., Abellan, X., Balsamo, G., Bechtold, P., Biavati, G., Bidlot, J., Bonavita, M., Chiara, G., Dahlgren, P., Dee, D., Diamantakis, M., Dragani, R., Flemming, J., Forbes, R., Fuentes, M., Geer, A., Haimberger, L., Healy, S., Hogan, R. J., Hólm, E., Janisková, M., Keeley, S., Laloyaux, P., Lopez, P., Lupu, C., Radnoti, G., Rosnay, P., Rozum, I., Vamborg, F., Villaume, S., and Thépaut, J.-N.: The ERA5 Global Reanalysis, Quarterly Journal of the Royal Meteorological Society, 146, 1999-2049, https://doi.org/10.1002/qj.3803, 2020.

Hewitson, B. and Crane, R.: Self-Organizing Maps: Applications to Synoptic Climatology, Climate Research, 22, 13-26, https://doi.org/10.3354/cr022013, 2002.

Holland, G. and Bruyère, C. L.: Recent Intense Hurricane Response to Global Climate Change, Climate Dynamics, 42, 617-627, https://doi.org/10.1007/s00382-013-1713-0, 2014.

Huang, B., Liu, C., Banzon, V., Freeman, E., Graham, G., Hankins, B., Smith, T., and Zhang, H.-M.: Improvements of the Daily Optimum Interpolation Sea Surface Temperature (DOISST) Version 2.1, Journal of Climate, 34, 2923-2939, https://doi.org/10.1175/JCLI-D-200166.1, 2021.

Jaye, A. B., Bruyère, C. L., and Done, J. M.: Understanding Future Changes in Tropical Cyclogenesis Using Self-Organizing Maps, Weather and Climate Extremes, 26, 100 235, https://doi.org/10.1016/j.wace.2019.100235, 2019.

Knapp, K. R., Kruk, M. C., Levinson, D. H., Diamond, H. J., and Neumann, C. J.: The International Best Track Archive for Climate Stewardship (IBTrACS), Bulletin of the American Meteorological Society, 91, 363-376, https://doi.org/10.1175/2009BAMS2755.1, 2010.

Knapp, K. R., Diamond, H. J., Kossin, J. P., Kruk, M. C., and Schreck, C. J. I.: International Best Track Archive for Climate Stewardship (IBTrACS) Project, Version 4., https://doi.org/10.25921/82ty-9e16, 2018.

Knutson, T., Camargo, S. J., Chan, J. C. L., Emanuel, K., Ho, C.-H., Kossin, J., Mohapatra, M., Satoh, M., Sugi, M., Walsh, K., and Wu, L.: 315 Tropical Cyclones and Climate Change Assessment: Part I: Detection and Attribution, Bulletin of the American Meteorological Society, 100, 1987-2007, https://doi.org/10.1175/BAMS-D-18-0189.1, 2019. 
https://doi.org/10.5194/wcd-2021-64

Preprint. Discussion started: 7 October 2021

(c) Author(s) 2021. CC BY 4.0 License.

(c) (i)

Weather and

Climate Dynamics

Discussions

Knutson, T., Camargo, S. J., Chan, J. C. L., Emanuel, K., Ho, C.-H., Kossin, J., Mohapatra, M., Satoh, M., Sugi, M., Walsh, K., and Wu, L.: Tropical Cyclones and Climate Change Assessment: Part II: Projected Response to Anthropogenic Warming, Bulletin of the American Meteorological Society, 101, E303-E322, https://doi.org/10.1175/BAMS-D-18-0194.1, 2020.

Kossin, J. P., Olander, T. L., and Knapp, K. R.: Trend Analysis with a New Global Record of Tropical Cyclone Intensity, Journal of Climate, 26, 9960-9976, https://doi.org/10.1175/JCLI-D-13-00262.1, 2013.

Kossin, J. P., Knapp, K. R., Olander, T. L., and Velden, C. S.: Global Increase in Major Tropical Cyclone Exceedance Probability over the Past Four Decades, Proceedings of the National Academy of Sciences, p. 201920849, https://doi.org/10.1073/pnas.1920849117, 2020.

Lin, N., Kopp, R. E., Horton, B. P., and Donnelly, J. P.: Hurricane Sandy's Flood Frequency Increasing from Year 1800 to 2100 , Proceedings of the National Academy of Sciences, 113, 12 071-12 075, https://doi.org/10.1073/pnas.1604386113, 2016.

Masson-Delmotte, V., Zhai, P., Pirani, A., Connors, L., Péan, C., Berger, S., Caud, N., Chen, Y., Goldfarb, L., Gomis, I. M., Huang, M., Leitzell, K., Lonnoy, E., Matthews, J. B. R., Maycock, T. K., Waterfield, T., Yelekçi, O., Yu, R., and Zhou, B.: IPCC, 2021: Climate Change 2021: The Physical Science Basis. Contribution of Working Group I to the Sixth Assessment Report of the Intergovernmental Panel on Climate Change, Cambridge University Press, In Press.

MunichRe: Tropical Storm Risks: Hurricanes, Typhoons, Cyclones I Munich Re, https://www.munichre.com/en/risks/natural-disasterslosses-are-trending-upwards/hurricanes-typhoons-cyclones.html, 2021.

Murakami, H., Levin, E., Delworth, T. L., Gudgel, R., and Hsu, P.-C.: Dominant Effect of Relative Tropical Atlantic Warming on Major Hurricane Occurrence, Science, 6711, eaat6711, https://doi.org/10.1126/science.aat6711, 2018.

Rayner, N. A.: Global Analyses of Sea Surface Temperature, Sea Ice, and Night Marine Air Temperature since the Late Nineteenth Century, Journal of Geophysical Research, 108, 4407, https://doi.org/10.1029/2002JD002670, 2003.

Reed, K. A., Stansfield, A. M., Wehner, M. F., and Zarzycki, C. M.: Forecasted Attribution of the Human Influence on Hurricane Florence, Science Advances, 6, eaaw9253, https://doi.org/10.1126/sciadv.aaw9253, 2020.

Sharmila, S. and Walsh, K. J. E.: Impact of Large-Scale Dynamical versus Thermodynamical Climate Conditions on Contrasting Tropical Cyclone Genesis Frequency, Journal of Climate, pp. JCLI-D-16-0900.1, https://doi.org/10.1175/JCLI-D-16-0900.1, 2017.

Shepherd, T. G.: A Common Framework for Approaches to Extreme Event Attribution, Current Climate Change Reports, 2, 28-38, https://doi.org/10.1007/s40641-016-0033-y, 2016.

Sippel, S., Meinshausen, N., Merrifield, A., Lehner, F., Pendergrass, A. G., Fischer, E., and Knutti, R.: Uncovering the Forced Climate Response from a Single Ensemble Member Using Statistical Learning, Journal of Climate, 32, 5677-5699, https://doi.org/10.1175/JCLID-18-0882.1, 2019.

Sobel, A. H., Camargo, S. J., Hall, T. M., Lee, C.-Y., Tippett, M. K., and Wing, A. A.: Human Influence on Tropical Cyclone Intensity, Science, 353, 242-246, https://doi.org/10.1126/science.aaf6574, 2016.

Trenberth, K. E., Fasullo, J. T., and Shepherd, T. G.: Attribution of Climate Extreme Events, Nature Climate Change, 5, 725-730, https://doi.org/10.1038/nclimate2657, 2015.

van Oldenborgh, G. J., van der Wiel, K., Sebastian, A., Singh, R., Arrighi, J., Otto, F., Haustein, K., Li, S., Vecchi, G., and

Cullen, H.: Attribution of Extreme Rainfall from Hurricane Harvey, August 2017, Environmental Research Letters, 12, 124009, https://doi.org/10.1088/1748-9326/aa9ef2, 2017.

Vecchi, G., Landsea, C., Zhang, W., Villarini, G., and Knutson, T.: Changes in Atlantic Major Hurricane Frequency Since the Late-19th Century, Preprint, In Review, https://doi.org/10.21203/rs.3.rs-153527/v1, 2021. 
https://doi.org/10.5194/wcd-2021-64

Preprint. Discussion started: 7 October 2021

(c) Author(s) 2021. CC BY 4.0 License.

(c) (i)

Weather and

Climate Dynamics

Discussions

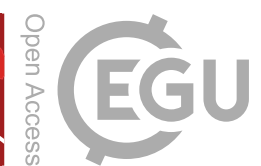

Walsh, K. J., McBride, J. L., Klotzbach, P. J., Balachandran, S., Camargo, S. J., Holland, G., Knutson, T. R., Kossin, J. P., Lee, T.c., Sobel, A., and Sugi, M.: Tropical Cyclones and Climate Change, Wiley Interdisciplinary Reviews: Climate Change, 7, 65-89, https://doi.org/10.1002/wcc.371, 2016. 